\title{
Menopausal hormone therapy and risk of cholecystectomy: a prospective study based on the French E3N cohort
}

\author{
Antoine Racine MD MSc, Anne Bijon MSc, Agnès Fournier PhD, Sylvie Mesrine MD, \\ Françoise Clavel-Chapelon PhD, Franck Carbonnel MD PhD, Marie-Christine Boutron-Ruault MD PhD
}

See related commentary by Liu on page 549 and at www.cmaj.ca/lookup/doi/10.1503/cmaj.130004

\begin{abstract}
Background: Studies in the United States and the United Kingdom have reported an increased risk of cholecystectomy among women exposed to menopausal hormone therapy, but with substantial heterogeneity between types of hormone treatments. We evaluated the risk of cholecystectomy associated with different regimens of menopausal hormone therapy in a large prospective cohort study.
\end{abstract}

Methods: Between 1992 and 2008, 70928 menopausal women from the French E3N study cohort were sent questionnaires assessing their use of menopausal hormone therapy, medical history and lifestyle characteristics. The primary outcome was cholecystectomy. We analyzed the risk of cholecystectomy associated with use of menopausal hormone therapy using Cox proportional models, with age as time-scale.

Results: During follow-up, 45984 (64.8\%) of the participants were exposed to menopausal hormone therapy, and 2819 cholecystectomies were recorded. The use of menopausal hormone therapy was associated with an increased risk of cholecystectomy (adjusted hazard ratio [HR] 1.10, 95\% confidence interval [Cl] 1.011.20) compared with women who were not exposed to menopausal hormone therapy. The association was restricted to unopposed oral estrogen therapy (adjusted HR 1.38, 95\% Cl 1.14-1.67). Over 5 years, about 1 cholecystectomy in excess would be expected in every 150 women using oral estrogen therapy without progestogens, compared with women not exposed to menopausal hormone therapy.

Interpretation: The risk of cholecystectomy was increased among women exposed to oral estrogen menopausal hormone therapy, especially oral regimens without a progestagen. Complicated gallstone disease should be added to the list of potential adverse events to be considered when balancing the benefits and risks associated with menopausal hormone therapy.
Competing interests: None declared.

Correspondence to: Antoine Racine, antoine_racine@yahoo.fr

CMAJ 2013. DOI:10.1503 /cmaj.121490
$\mathrm{G}$ allstone disease is common in developed countries, ${ }^{1}$ and complications of gallstones represent a major reason for hospital admission and greatly contribute to health care costs and patient morbidity. ${ }^{2}$ Among women, those over 50 years of age are at greatest risk of gallstone disease. ${ }^{3}$ Other known risk factors are obesity, multiparity, dyslipidemia, hyperinsulinism, inappropriate dietary intake and genetic predisposition. ${ }^{4-8}$ Studies in the United States and the United Kingdom have reported an increased risk of cholecystectomy among women exposed to menopausal hormone therapy. ${ }^{9-14}$ No data are available in France, where menopausal hormone therapy regimens are different from those most commonly used in the US and UK (predominance of the transdermal over oral route, infrequent use of equine estrogens, and frequent use of progesterone and its isomer, dydrogesterone, as the progestagen component). In addition, the impact of progestagens used in menopausal hormone therapy regimens remains unclear with regard to gallstone risk.

We prospectively evaluated the risk for cholecystectomy among women exposed to different menopausal hormone therapy regimens in a French cohort study.

\section{Methods}

\section{Study design}

The Étude Épidémiologique de femmes de la Mutuelle Générale de l'Éducation Nationale (E3N) is a large prospective cohort study conducted in France to investigate hormonal and environmental factors involved in female diseases. The study design, population and collection of baseline data have been described previously. ${ }^{15}$ In brief, 98995 women insured by the 
national health insurance plan for teachers and coworkers were enrolled in 1990 and asked to complete a questionnaire every 2 years that addressed medical history, reproductive history, dietary habits, and anthropometry and lifestyle characteristics. ${ }^{16}$ All participants gave informed consent, in accordance with the rules of the French National Commission for Data Protection and Privacy.

\section{Study population}

Of the 98995 women in the E3N cohort, we included 70928 in our study. We excluded those who had a history of cholecystectomy $(n=4588)$ or cancer other than basal cell skin carcinoma $(n=4175)$ before recruitment in that study, those without any menstrual period $(n=28)$, those who were not menopausal before the end of follow-up $(n=6209)$, those who did not answer the baseline questionnaire in $1992(n=8117)$ and the 4950 women who were lost to follow-up after inclusion. We defined baseline as January 1992 for women who were already menopausal by that date, or the date of the first questionnaire following their menopause. Women contributed person-years of follow-up until the date of cholecystectomy, the date of the last completed questionnaire or June 30, 2008 (the date at which the ninth questionnaire was sent to participants), whichever occurred first.

\section{Data collection}

Information on menopausal hormone therapy and other covariates was collected at inclusion in January 1992 and updated at the time of each subsequent questionnaire. For each episode of menopausal hormone therapy, the start date, duration and brand names of the products used were recorded, as described previously. ${ }^{17}$ Data on other covariates were also updated during follow-up, except parity, breastfeeding, age at menarche and education level, which were recorded in the baseline questionnaire. Dietary data were collected in June 1993 with use of a validated questionnaire on diet history. ${ }^{18,19}$

Cholecystectomy and first diagnosis of gallstones, along with their respective dates, were self-reported by the participants. A validation study was performed on 3 random samples: 100 women with self-reported cholecystectomy, 100 who reported having untreated gallstones and 50 with no declaration of gallstone disease or cholecystectomy. These 250 women were sent a detailed questionnaire that requested documents relative to diagnostic and surgical procedures. Concordance between the documents and the self-reports of a history or absence of history of cholecystectomy was excellent (99\%); concor- dance regarding gallstone disease was less satisfactory (67\%) (Appendix 1, available at www .cmaj.ca/lookup/suppl/doi:10.1503/cmaj.121490 /-/DC1). Thus, cholecystectomy was chosen as the primary outcome of our study.

\section{Statistical analysis}

We estimated the risk of cholecystectomy associated with exposure to menopausal hormone therapy using Cox proportional hazard models for left-truncated and right-censored data, with age as time-scale. Results are reported as hazard ratios (HRs) and 95\% confidence intervals (CIs). Use of menopausal hormone therapy was analyzed as a time-dependent variable and dealt with prospectively: the information reported in questionnaires $t$ and earlier was used to prospectively categorize participants for the period between completion of questionnaires $t$ and $t+1$. For women who did not answer questionnaire $t$, their status of exposure to menopausal hormone therapy was classified as missing for the period between the date when questionnaire $t$ was sent to the participants and the date of completion of the subsequent questionnaire.

Menopausal hormone therapy was first categorized as a global exposure (never, past or current use) and then according to cumulative exposure to estrogen (oral estradiol, oral equine estrogens, transdermal estradiol, and other estrogens including vaginally or nasally administered estrogens) and progestagen (none, progesterone, pregnanes, norpregnanes and testosterone derivatives). If a woman received successively different regimens, she was simultaneously accounted for in the corresponding categories. For example, if at a given time a woman was both a current user of transdermal estradiol and a past user of oral estradiol, she contributed person-years to both categories. In the subgroup of women exposed to only one type of regimen, we analyzed the effect of duration of use ( $<6 \mathrm{yr}$ v. $\geq 6 \mathrm{yr}$ [ $6 \mathrm{yr}$ being the median]) among current users, and the recency of use (current v. past use; and time since last use according to the median, as $<11 \mathrm{yr} \mathrm{v} . \geq 11 \mathrm{yr}$ ). Models were systematically adjusted for body mass index (BMI) (time-dependent: < 18.5, $18.5-22.5,22.5-25,25-30$ and $\left.\geq 30 \mathrm{~kg} / \mathrm{m}^{2}\right)$, parity $(0,1,2-3$ and $>3$ children), hypercholesterolemia and diabetes (time-dependent: no or yes), education level (secondary school, 1-3 yr of university and $>3 \mathrm{yr}$ of university). We compared HRs using the Wald $\chi^{2}$ test of homogeneity. Potential interactions between covariates and regimens of menopausal hormone therapy were explored in Cox models.

We examined other potential confounders, including physical activity, previous use of oral 
contraceptives, type of menopause (artificial or natural), age at menopause, age at menarche, age at first pregnancy, history of hysterectomy, history of breastfeeding and history of benign thyroid disease. For the 61026 women with available dietary data, models were also adjusted for intake of polyunsaturated fatty acids, simple sugars, dietary fibre, alcohol and coffee (in quartiles). Covariates were included in the final adjusted model if they were significantly associated with risk of cholecystectomy or if they changed the estimate associated with ever use of menopausal hormone therapy by more than $10 \%$. Missing data for adjustment variables were imputed by means of a multiple imputation procedure. ${ }^{20}$ We explored potential interactions between use of menopausal hormone therapy and covariates by including an interaction term in the models.

We calculated incident rates of cholecystectomy according to the various regimens of menopausal hormone therapy. Absolute risks were calculated among women who never used menopausal hormone therapy (reference) and in the treatment groups, considering the multivariable models.
All statistical tests were 2-sided, and statistical significance was set at the 0.05 level. We used SAS version 9.2 (SAS Institute, Inc., Cary, North Carolina) to perform all analyses.

\section{Results}

Overall, 70928 women were included; the mean follow-up period was 11.5 years, for a total of 819889 person-years of follow-up. During the study period, $45984(64.8 \%)$ of the women reported ever using menopausal hormone therapy. The baseline characteristics of the participants are shown in Table 1 according to their exposure menopausal hormone therapy. Overall, 78435 courses of treatment with menopausal hormone therapy were recorded (Table 2). The main route of estrogen administration was transdermal. Most of the estrogens were in combined formulations with progestagens. Oral equine estrogens use was infrequent.

During follow-up, 2819 incident cholecystectomies were recorded. There was a positive association between risk of cholecystectomy and increasing BMI, higher parity, hypercholesterolemia, diabetes and education level (data not

Table 1: Baseline characteristics of 70928 participants from the E3N cohort, by use of menopausal hormone therapy during follow-up

\begin{tabular}{|c|c|c|c|c|c|}
\hline \multirow[b]{2}{*}{ Characteristic } & \multicolumn{2}{|c|}{ Use of menopausal hormone therapy* } & \multicolumn{3}{|c|}{ Type of regimen used } \\
\hline & $\begin{array}{c}\text { Never } \\
n=18694\end{array}$ & $\begin{array}{c}\text { Ever } \\
n=45984\end{array}$ & $\begin{array}{c}\text { Transdermal } \\
\text { estrogen } \\
n=33584\end{array}$ & $\begin{array}{l}\text { Oral estrogen } \\
n=16736\end{array}$ & $\begin{array}{l}\text { Other estrogen } \\
\quad n=6709\end{array}$ \\
\hline $\begin{array}{l}\text { Length of follow-up, yr, } \\
\text { mean (IQR) }\end{array}$ & $10.5(5.8-15.9)$ & $12.1(7.9-16.2)$ & $12.6(10.1-16.4)$ & $11.9(10.9-16.3)$ & $12.0(7.9-16.3)$ \\
\hline Age, yr, mean \pm SD & $56.4 \pm 4.7$ & $53.9 \pm 4.1$ & $53.8 \pm 4.0$ & $53.2 \pm 3.9$ & $53.7 \pm 4.0$ \\
\hline $\begin{array}{l}\text { Education level } \geq \text { high school, } \dagger \\
\text { no. }(\%)\end{array}$ & $15986(85.5)$ & $41181(89.6)$ & 30049 (89.5) & $15119(90.3)$ & $6075(90.6)$ \\
\hline $\mathrm{BMI},+\mathrm{kg} / \mathrm{m}^{2}$, mean $\pm \mathrm{SD}$ & $23.3 \pm 3.7$ & $22.4 \pm 2.8$ & $22.4 \pm 2.8$ & $22.2 \pm 2.7$ & $22.3 \pm 2.7$ \\
\hline Parity, $†$ mean \pm SD & $1.8 \pm 1.2$ & $1.8 \pm 1.1$ & $1.8 \pm 1.1$ & $1.8 \pm 1.1$ & $1.8 \pm 1.1$ \\
\hline Hypercholesterolemia, no. (\%) & $623(3.3)$ & 1318 (2.9) & $997 \quad(3.0)$ & $393(2.3)$ & $188(2.8)$ \\
\hline Diabetes mellitus, no. (\%) & $262(1.4)$ & $281(0.6)$ & $213(0.6)$ & $77(0.5)$ & $31(0.5)$ \\
\hline Hysterectomy, no. (\%) & $3011(16.1)$ & $9404(20.5)$ & $7476(22.3)$ & $2965(17.7)$ & $1225(18.3)$ \\
\hline $\begin{array}{l}\text { History of gallstone disease not } \\
\text { requiring surgery, no. (\%) }\end{array}$ & $341 \quad(1.8)$ & 749 (1.6) & $563(1.7)$ & $257(1.5)$ & $94 \quad(1.4)$ \\
\hline $\begin{array}{l}\text { Physical activity, }+ \text { MET-h/wk, } \\
\text { mean } \pm \text { SD }\end{array}$ & $44.2 \pm 28.5$ & $42.0 \pm 26.2$ & $41.7 \pm 25.9$ & $41.9 \pm 26.4$ & $41.6 \pm 25.5$ \\
\hline Artificial menopause, †‡ no. (\%) & 1741 & 3936 (8.6) & $3047 \quad(9.1)$ & $1323(7.9)$ & $505 \quad(7.5)$ \\
\hline $\begin{array}{l}\text { Ever use of oral contraceptives, } \\
\text { no. }(\%)\end{array}$ & $9310(49.8)$ & $29602(64.4)$ & $21371(63.6)$ & $11774(70.4)$ & $4588(68.4)$ \\
\hline History of breastfeeding + no. (\%) & $10965(58.7)$ & $27741(60.3)$ & $20195(60.1)$ & $10158(60.7)$ & $4079(60.8)$ \\
\hline \multicolumn{6}{|c|}{$\begin{array}{l}\text { Note: BMI = body mass index, E3N = Étude Épidémiologique de femmes de la Mutuelle Générale de l'Éducation Nationale, IQR = interquartile range, MET-h/wk = } \\
\text { metabolic equivalent hours per week, SD = standard deviation. } \\
\text { *Data on use of menopausal hormone therapy were missing for } 6250 \text { women, including } 211 \text { who reported undergoing cholecystectomy during follow-up. } \\
\text { tData were missing on education level for } 2841 \text { women, on BMI for } 76 \text {, on parity for } 523 \text {, on physical activity for } 779 \text {, on status of artificial menopause for } 1229 \\
\text { and on breastfeeding for } 523 \text { women. } \\
\text { fArtificial menopause due to bilateral oophorectomy or to a specific medical condition (induced by radiation or a drug). }\end{array}$} \\
\hline
\end{tabular}


shown). Data on the use of menopausal hormone therapy were available for 2608 women who underwent cholecystectomy. Compared with

Table 2: Types of regimens of menopausal hormone therapy used

\begin{tabular}{|lrl|l|}
\hline Regimen & No. (\%) of treatments* \\
\hline Transdermal estrogen & 48846 & $(62.3)$ \\
\hline Without progestagen & $9488(12.1)$ \\
\hline With progesterone & 534 & $(26.2)$ \\
\hline With pregnane derivative & 649 & $(8.2)$ \\
\hline With norpregnane derivative & $11370(14.5)$ \\
\hline With testosterone derivative & 518 & $(0.7)$ \\
\hline With other progestagen & 487 & $(0.6)$ \\
\hline Oral estrogen & $22880(29.2)$ \\
\hline Estradiol & 21498 & $(27.4)$ \\
\hline Without progestagen & 1713 & $(2.2)$ \\
\hline With progesterone & 4940 & $(6.3)$ \\
\hline With pregnane derivative & 7121 & $(9.1)$ \\
\hline With norpregnane derivative & 2775 & $(3.5)$ \\
\hline With testosterone derivative & 4822 & $(6.1)$ \\
\hline With other progestagen & 127 & $(0.2)$ \\
\hline Oral equine estrogen & 1382 & $(1.8)$ \\
\hline Without progestagen & 585 & $(0.7)$ \\
\hline With progesterone & 219 & $(0.3)$ \\
\hline With pregnane derivative & 311 & $(0.4)$ \\
\hline With norpregnane derivative & 193 & $(0.2)$ \\
\hline With testosterone derivative & 45 & $(0.1)$ \\
\hline With other progestagen & 29 & $(0.04)$ \\
\hline Other estrogen & $(8.6)$ \\
\hline *Each course of menopausal hormone therapy is counted separately. The total courses of \\
treatment was 78 435 among 45 984 women. & & \\
\hline & & \\
\hline
\end{tabular}

women who never used menopausal hormone therapy, those who ever used it had an increased risk of cholecystectomy (adjusted HR 1.10, 95\% CI 1.01-1.20) (Table 3). The association was restricted to use of oral estrogens (adjusted HR 1.16 , 95\% CI 1.06-1.27). Other types of regimens were not associated with an increased risk. Risk was significantly higher with oral estrogens than with transdermal estrogens $(p=0.03)$. Risk was also significantly higher with oral estrogens used alone (unopposed estrogens) than with oral estrogens combined with a progestagen ( $p=$ 0.03) (Table 3). When we looked at the difference in risk of cholecystectomy by type of oral estrogen, the risk was significantly higher with oral equine estrogens alone than with oral equine estrogens combined with a progestagen $(p=$ $0.01)$. We found no significant difference between women who used oral estradiol therapy alone and those who used oral equine estrogens alone $(p=0.4)$ or oral estradiol with a progestagen $(p=0.2)$ (Table 4).

In the sensitivity analysis in which we included women exposed to only one type of menopausal hormone therapy during follow-up (25 654 [55.8\%] of 45984 who ever used such therapy), the risk of cholecystectomy was associated with use of unopposed oral estradiol therapy (adjusted HR 1.83, 95\% CI 1.18-2.86) and use of unopposed oral equine estrogen therapy (adjusted HR 1.90, 95\% CI 1.17-2.11) compared with women who never used menopausal hormone therapy (Table 5). Other types of regimens were not associated with an increased risk of cholecystectomy. Among current users of unopposed oral estrogen therapy, we found no difference in risk by duration of exposure ( $<6 \mathrm{yr}$ v. $\geq 6 \mathrm{yr} ; p=0.6)$. We

Table 3: Incidence of cholecystectomy and risk associated with use of menopausal hormone therapy

\begin{tabular}{|c|c|c|c|c|}
\hline Variable & No. of women* & $\begin{array}{c}\text { No. who had } \\
\text { cholecystectomy* }\end{array}$ & $\begin{array}{l}\text { Age-adjusted HR } \\
(95 \% \mathrm{Cl})\end{array}$ & $\begin{array}{c}\text { Multivariate HR }+ \\
(95 \% \mathrm{Cl})\end{array}$ \\
\hline Never used menopausal hormone therapy & 18694 & 824 & 1.00 (ref) & 1.00 (ref) \\
\hline Oral estrogen & 16736 & 625 & $1.10(1.00-1.20)$ & $1.16(1.06-1.27) \ddagger$ \\
\hline Oral estrogen alone & 2229 & 118 & $1.36(1.03-1.65)$ & $1.38(1.14-1.67) \S$ \\
\hline Transdermal estrogen & 33584 & 1300 & $0.97(0.89-1.04)$ & $1.01(0.94-1.10)$ \\
\hline Transdermal estrogen alone & 9488 & 361 & $1.06(0.95-1.19)$ & $1.04(0.93-1.17)$ \\
\hline Transdermal estrogen with progestagen & 30444 & 1165 & $0.93(0.87-1.01)$ & $0.99(0.91-1.07)$ \\
\hline Other estrogen & 6709 & 187 & $1.01(0.87-1.17)$ & $1.03(0.89-1.20)$ \\
\hline \multicolumn{5}{|c|}{$\begin{array}{l}\text { Note: } \mathrm{Cl}=\text { confidence interval, } \mathrm{HR}=\text { hazard ratio, ref }=\text { reference group. } \\
\text { *Data on use of menopausal hormone therapy were missing for } 6250 \text { women, including } 211 \text { who reported undergoing cholecystectomy during follow-up. } \\
\text { †Adjusted for body mass index, parity, hypercholesterolemia, diabetes and educational level. } \\
\neq p=0.03 \text { for comparison of oral estrogen v. transdermal estrogen; } p=0.2 \text { for comparison of oral estrogen v. other estrogen. } \\
\S p=0.03 \text { for comparison of oral estrogen alone v. oral estrogen with progestagen. }\end{array}$} \\
\hline
\end{tabular}


also found no difference when we compared current and past use $(p=0.2)$ and time since last use ( $<11 \mathrm{yr}$ v. $\geq 11 \mathrm{yr} ; p=0.6$ ). Among progestagen users, there was no difference in risk by type of progestagen $(p=0.6)$ (data not shown). There was no interaction between exposure to menopausal hormone therapy and BMI, parity, period of follow-up (before v. after 2003), presence of hypercholesterolemia or diabetes, hysterectomy or history of gallstones at baseline (data not shown). Among women for whom dietary data were available, additional adjustment for dietary intake did not modify the findings (data not shown).

Among women who had undergone cholecystectomy during follow-up, those exposed to oral estrogens $(n=625)$ were younger at the time of cholecystectomy $(p<0.001)$, leaner $(p<0.001)$ and less likely to have a history of gallstones at baseline $(p<0.001)$ than women with no exposure to menopausal hormone therapy $(n=824)$. They were also somewhat less likely to be nulliparous $(p=0.09)$ (data not shown).

The absolute risk of cholecystectomy was 49 per 10000 person-years among women who reported ever using menopausal hormone therapy and 35 per 10000 person-years among those who reported no exposure. From these rates, over 5 years, about 1 cholecystectomy in excess would be expected in every 150 women using oral estrogen therapy without a progestagen, compared with women not exposed to menopausal hormone therapy.

\section{Interpretation}

In this large French prospective cohort study, we found that the risk of cholecystectomy was increased among women exposed to oral estrogen regimens for menopausal hormone therapy, especially oral regimens without a progestagen. Other types of menopausal hormone therapy were not associated with an increased risk of cholecystectomy.

Our findings are in agreement with those from previous reports of an increased risk of cholecystectomy associated with menopausal hormone therapy. ${ }^{9-14}$ Associations with unopposed oral estrogen therapy were stronger in other studies, such as the Million Women Study and the Women's Health Initiative, ${ }^{9,12}$ than in ours. However, we observed stronger associations when we restricted the analysis to women exposed to a single treatment type, which suggests a diluting effect by the multiplicity of types of menopausal hormone therapy in our population compared with other studies. We did not observe any increased risk of cholecystectomy associated with transdermal estrogen use, which is in partial agreement with a weaker association with transdermal compared with oral estrogen use reported in the Million Women Study. ${ }^{9}$

We found no association between oral estrogen use and cholecystectomy risk when the regimens included a progestagen. These results contrast with those from previous studies where the risk was not modified by progestagens. ${ }^{9}, 12$ However, the types of progestagens were more diverse in our study than in the Women's Health Initiative, ${ }^{12}$ in which only medroxy-progesterone acetate was used, or the Million Women Study, in which progestagens were essentially norpregnanes or medroxy-progesterone. We cannot exclude that differences in the progestagen molecules used could account for differences in the associations observed between our study and previous reports.

Beyond the specificities of the menopausal hormone therapy regimens, some differences in the characteristics of the study populations could explain the different findings. However, we observed no confounding effect on the risk of cholecystectomy between use of menopausal hormone therapy and known acquired risk factors for gallbladder disease. Hereditary factors ${ }^{21-23}$ and specific

Table 4: Incidence of cholecystectomy and risk associated with use of oral estrogen menopausal hormone therapy

\begin{tabular}{|c|c|c|c|c|}
\hline Variable & $\begin{array}{c}\text { No. of } \\
\text { women* }\end{array}$ & $\begin{array}{c}\text { No. who had } \\
\text { cholecystectomy* }\end{array}$ & $\begin{array}{l}\text { Age-adjusted HR } \\
(95 \% \mathrm{Cl})\end{array}$ & $\begin{array}{l}\text { Multivariate HRt } \\
(95 \% \mathrm{Cl})\end{array}$ \\
\hline Never used menopausal hormone therapy & 18694 & 824 & 1.00 (ref) & 1.00 (ref) \\
\hline Ever used oral estrogen therapy & 16736 & 625 & $1.06(0.96-1.16)$ & $1.16(1.06-1.27)$ \\
\hline Estradiol alone & 1713 & 77 & $1.25(0.99-1.57)$ & $1.27(1.01-1.60) \ddagger$ \\
\hline Estradiol with progestagen & 15261 & 533 & $1.03(0.93-1,13)$ & $1.10(0.99-1.21)$ \\
\hline Equine estrogen alone & 585 & 44 & $1.48(1.09-2.00)$ & $1.53(1.11-2.11) \S$ \\
\hline Equine estrogen with progestagen & 599 & 23 & $0.95(0.67-1.34)$ & $0.68(0.43-1.09)$ \\
\hline \multicolumn{5}{|c|}{$\begin{array}{l}\text { Note: } \mathrm{Cl}=\text { confidence interval, } \mathrm{HR}=\text { hazard ratio, ref }=\text { reference group. } \\
\text { *Data on use of menopausal hormone therapy were missing for } 6250 \text { women, including } 211 \text { who reported undergoing cholecystectomy during follow-up. } \\
\text { †Adjusted for body mass index, parity, hypercholesterolemia, diabetes and education level. } \\
\neq p=0.2 \text { for comparison of estradiol alone } v \text {. estradiol with progestagen; } p=0.4 \text { for comparison of estradiol alone v. equine estrogen alone. } \\
\S p=0.01 \text { for comparison of equine estrogen alone v. equine estrogen with progestagen. }\end{array}$} \\
\hline
\end{tabular}


genetic polymorphisms ${ }^{24}$ that modulate the risk of gallstone disease and the hepatic response to estrogen exposure could account for some of the differences observed across populations.

Unlike the Million Women Study, we studied only surgically treated gallstone disease because concordance was not sufficient regarding untreated gallstone disease in the validation study. Therefore, some symptomatic gallstone disease may have gone undiagnosed, which may have resulted in some degree of outcome misclassification and therefore a weakening of the associations observed.

Pharmacologic data are consistent with epidemiologic studies: estrogens modify lipid metabolism, increase biliary cholesterol secretion and saturation, ${ }^{22-27}$ and promote precipitation of cholesterol in the bile. Estrogens reduce gallbladder motility, which increases bile crystallization ${ }^{26}$ and contributes to gallstone formation. The transdermal route of administration bypasses involvement of the liver and thus does not increase biliary cholesterol saturation, which could account for the lower risk of complicated gallstone disease associated with transdermal estradiol use than with oral estradiol use. ${ }^{27}$ Hepatobiliary effects of progestagens have been explored to a lesser extent than those of estrogens. ${ }^{26}$

The E3N cohort study has assessed the impact of menopausal hormone therapy on several outcomes, including breast cancer, ${ }^{17,28}$ diabetes onset, ${ }^{29}$ thromboembolic events ${ }^{30}$ and asthma. ${ }^{31}$ Unlike most reports from cohort studies in which exposure to menopausal hormone therapy is assessed only at baseline, data on the use of menopausal hormone therapy and covariates in the E3N cohort were updated every 2 years during the follow-up period. These updates allowed us to determine the use of menopausal hormone therapy more precisely, reduced misclassification bias and allowed a better adjustment of models. In our study, less than $5 \%$ of women had missing data on covariates, and loss to follow-up was uncommon. The size of the cohort, the large number of events and the long follow-up period conferred a high statistical power; however, power was reduced in subgroup analyses, especially when we restricted exposure to a small proportion of women. Thus, the lack of interaction between exposure and other covariates may have been due to reduced statistical power for those analyses.

\section{Limitations}

Our study has limitations. Exposure to menopausal hormone therapy and the occurrence of cholecystectomy were self-reported. However, the study population was composed mostly of highly adherent and educated women. To limit record bias regarding use of menopausal hormone therapy, we used a booklet with colour photographs and names of all of the relevant products marketed in France. Regarding the outcome, the validation study showed excellent concordance between self-reports and validated reports of cholecystectomy. Thus, missing data and case misclassification are unlikely to explain our findings. Nevertheless, because the medical indication for cholecystectomy was available only for the small sample of women in the validation study, it is difficult to conclude whether menopausal hormone therapy promotes gallstones per se or its complications. Extrapolation of our

\begin{tabular}{|c|c|c|c|}
\hline Variable & $\begin{array}{c}\text { No. of } \\
\text { women* }\end{array}$ & $\begin{array}{c}\text { No. who had } \\
\text { cholecystectomy* }\end{array}$ & $\begin{array}{c}\text { Multivariate HR } \dagger \\
(95 \% \mathrm{Cl})\end{array}$ \\
\hline Never used menopausal hormone therapy & 18694 & 824 & 1.00 (ref) \\
\hline Oral estradiol alone & 277 & 20 & $1.83(1.18-2.86) \ddagger$ \\
\hline Oral estradiol with progestagen & 5930 & 232 & $1.18(0.89-1.55)$ \\
\hline Oral equine estrogen alone & 157 & 17 & $1.90(1.17-2.11) \S$ \\
\hline Oral equine estrogen with progestagen & 91 & 10 & $1.64(0.88-3.06)$ \\
\hline Transdermal estrogen alone & 2166 & 101 & $1.20(0.97-1.47)$ ๆ \\
\hline Transdermal estrogen with progestagen & 15481 & 674 & $1.05(0.95-1.16)$ \\
\hline Other estrogen & 1552 & 38 & $0.93(0.67-1.29)$ \\
\hline \multicolumn{4}{|c|}{$\begin{array}{l}\text { Note: } \mathrm{Cl}=\text { confidence interval, } \mathrm{HR}=\text { hazard ratio, ref }=\text { reference group. } \\
\text { *Data on use of menopausal hormone therapy were missing for } 6250 \text { women, including } 211 \text { who reported undergoing } \\
\text { cholecystectomy during follow-up. } \\
\text { †Adjusted for body mass index, parity, hypercholesterolemia, diabetes and educational level. } \\
\neq p=0.06 \text { for comparison of oral estradiol alone } v \text {. oral estradiol with progestagen; } p=0.9 \text { for comparison of oral estradiol } \\
\text { alone } v \text {. oral equine estrogen alone; } p=0.08 \text { for comparison of oral estradiol alone v. oral transdermal estrogen alone; } p=0.02 \\
\text { for comparison of oral estradiol alone v. other estrogen. } \\
\$ p=0.7 \text { for comparison of oral equine estrogen alone } v \text {. oral equine estrogen with progestagen. } \\
\uparrow p=0.3 \text { for comparison of transdermal estrogen alone } v \text {. transdermal estrogen with progestagen. }\end{array}$} \\
\hline
\end{tabular}


findings to the general population should be done with caution, because the study population comprised women insured by France's national health insurance plan for teachers and coworkers, a cohort with a higher mean education level than in the overall French population.

\section{Conclusion}

The risk of cholecystectomy was increased among women exposed to oral estrogen menopausal hormone therapy, especially oral regimens without a progestagen. Complicated gallstone disease should be added to the list of potential adverse events to be considered when balancing the benefits and risks associated with menopausal hormone therapy.

\section{References}

1. Portincasa P, Moschetta A, Palasciano G. Cholesterol gallstone disease. Lancet 2006;368:230-9.

2. Ruhl CE, Everhart JE. Gallstone disease is associated with increased mortality in the United States. Gastroenterology 2011;140:508-16.

3. Heaton KW, Braddon FE, Mountford RA, et al. Symptomatic and silent gall stones in the community. Gut 1991;32:316-20.

4. Tsai C-J, Leitzmann MF, Willett WC, et al. Central adiposity, regional fat distribution, and the risk of cholecystectomy in women. Gut 2006;55:708-14.

5. Tsai C-J, Leitzmann MF, Willett WC, et al. Glycemic load, glycemic index, and carbohydrate intake in relation to risk of cholecystectomy in women. Gastroenterology 2005;129:105-12.

6. Boland LL, Folsom AR, Rosamond WD. Hyperinsulinemia, dyslipidemia, and obesity as risk factors for hospitalized gallbladder disease. A prospective study. Ann Epidemiol 2002;12:131-40.

7. Niemi M, Kervinen K, Rantala A, et al. The role of apolipoprotein $\mathrm{E}$ and glucose intolerance in gallstone disease in middle aged subjects. Gut 1999;44:557-62.

8. Everhart JE, Khare M, Hill M, et al. Prevalence and ethnic differences in gallbladder disease in the United States. Gastroenterology 1999;117:632-9.

9. Liu B, Beral V, Balkwill A, et al.; Million Women Study Collaborators. Gallbladder disease and use of transdermal versus ora hormone replacement therapy in postmenopausal women: prospective cohort study. BMJ 2008;337:a386.

10. Mamdani MM, Tu K, van Walraven C, et al. Postmenopausal estrogen replacement therapy and increased rates of cholecystectomy and appendectomy. CMAJ 2000;162:1421-4.

11. Grodstein F, Colditz GA, Stampfer MJ. Postmenopausal hormone use and cholecystectomy in a large prospective study. Obstet Gynecol 1994;83:5-11.

12. Cirillo DJ, Wallace RB, Rodabough RJ, et al. Effect of estrogen therapy on gallbladder disease. JAMA 2005;293:330-9.

13. Simon JA, Hunninghake DB, Agarwal SK, et al. Effect of estrogen plus progestin on risk for biliary tract surgery in postmenopausal women with coronary artery disease. The Heart and Estrogen/progestin Replacement Study. Ann Intern Med 2001; 135:493-501.

14. Farquhar C, Marjoribanks J, Lethaby A, et al. Long term hormone therapy for perimenopausal and postmenopausal women. Cochrane Database Syst Rev 2009; (2):CD004143.

15. Clavel-Chapelon F, van Liere MJ, Giubout C, et al. E3N, a French cohort study on cancer risk factors. E3N Group. Etude Epidémiologique auprès de femmes de l'Education Nationale. Eur J Cancer Prev 1997;6:473-8.

16. Riboli E. Nutrition and cancer: background and rationale of the European Prospective Investigation into Cancer and Nutrition (EPIC). Ann Oncol 1992;3:783-91.

17. Fournier A, Mesrine S, Boutron-Ruault MC, et al. Estrogenprogestagen menopausal hormone therapy and breast cancer: Does delay from menopause onset to treatment initiation influence risks? J Clin Oncol 2009;27:5138-43.

18. van Liere MJ, Lucas F, Clavel F, et al. Relative validity and reproducibility of a French dietary history questionnaire. Int $J$ Epidemiol 1997;26(Suppl 1):S128-36.

19. Lucas F, Niravong M, Villeminot S, et al. Estimation of food portion size using photographs: validity, strengths, weaknesses and recommendations. J Hum Nutr Diet 1995;8:65-74.
20. Kmetic A, Joseph L, Berger C, et al. Multiple imputation to account for missing data in a survey: estimating the prevalence of osteoporosis. Epidemiology 2002;13:437-44.

21. Friedrich N, Völzke H, Hampe J, et al. Known risk factors do not explain disparities in gallstone prevalence between Denmark and northeast Germany. Am J Gastroenterol 2009;104:89-95.

22. Wang HH, Portincasa P, Wang DQ-H. Molecular pathophysiology and physical chemistry of cholesterol gallstones. Front Biosci 2008;13:401-23.

23. Buch S, Schafmayer C, Völzke H, et al. Loci from a genome-wide analysis of bilirubin levels are associated with gallstone risk and composition. Gastroenterology 2010;139(6):1942-51.e2.

24. Wang HH, Liu M, Clegg DJ, et al. New insights into the molecular mechanisms underlying effects of estrogen on cholesterol gallstone formation. Biochim Biophys Acta 2009;1791:1037-47.

25. Uhler ML, Marks JW, Judd HL. Estrogen replacement therapy and gallbladder disease in postmenopausal women. Menopause 2000; 7:162-7.

26. Dhiman RK, Sarkar PK, Sharma A, et al. Alterations in gallbladder emptying and bile retention in the absence of changes in bile lithogenicity in postmenopausal women on hormone replacement therapy. Dig Dis Sci 2004;49:1335-41.

27. Van Erpecum KJ, Van Berge Henegouwen GP, Verschoor L, et al. Different hepatobiliary effects of oral and transdermal estradiol in postmenopausal women. Gastroenterology 1991;100:482-8.

28. Fournier A, Fabre A, Mesrine S, et al. Use of different postmenopausal hormone therapies and risk of histology- and hormone receptor-defined invasive breast cancer. J Clin Oncol 2008;26:1260-8.

29. de Lauzon-Guillain B, Fournier A, Fabre A, et al. Menopausal hormone therapy and new-onset diabetes in the French Etude Epidemiologique de Femmes de la Mutuelle Générale de l'Education Nationale (E3N) cohort. Diabetologia 2009;52:2092-100.

30. Canonico M, Fournier A, Carcaillon L, et al. Postmenopausal hormone therapy and risk of idiopathic venous thromboembolism: results from the E3N cohort study. Arterioscler Thromb Vasc Biol 2010;30:340-5.

31. Romieu I, Fabre A, Fournier A, et al. Postmenopausal hormone therapy and asthma onset in the E3N cohort. Thorax 2010;65: 292-7.

Affiliations: From the Institut national de la santé et de la recherche médicale (INSERM), the Centre for Research in Epidemiology and Population Health and Université Paris Sud (Racine, Bijon, Fournier, Mesrine, Clavel-Chapelon, Carbonnel, Boutron-Ruault), Villejuif, France; and the Department of Hepatogastroenterology (Racine, Carbonnel), Hôpital Bicêtre, Assistance Publique Hôpitaux de Paris, Université Paris-Sud, Le Kremlin Bicêtre, France

Contributors: Antoine Racine, Anne Bijon and MarieChristine Boutron-Ruault contributed to the study design, data collection, design and implementation of the statistical analysis, interpretation of results, and the drafting and review of the manuscript. Franck Carbonnel and Sylvie Mesrine contributed to interpretation of results, and the drafting and review of the manuscript. Agnès Fournier contributed to the study design, the design and implementation of the statistical analysis, and the review of the manuscript. Françoise ClavelChapelon set up and is in charge of the E3N cohort; she contributed to the study design and implementation, and the drafting and review of the manuscript. All of the authors approved the final manuscript submitted for publication.

Funding: The E3N cohort is being studied with the financial support of the Mutuelle générale de l'éducation nationale, the European Community, the Ligue nationale contre le cancer, the Institut Gustave-Roussy, INSERM, and a grant from the World Cancer Research Fund (grant no. 2007/14). The current study was funded by a grant from Assistance publique hôpitaux de Paris. The study sponsors had no role in the design of the study, the collection, analysis or interpretation of data, the writing of the report or the decision to submit the article for publication.

Acknowledgments: The authors are indebted to all of the women in the cohort for providing the data used in the E3N study. They are grateful to Sophie Morois, Lyan Hoang, Maryvonne Niravong, Marie Fangon and Maxime Valdenaire for their technical assistance. 